\title{
Sieve-type normal pore canals in Jurassic ostracods: A review with description of a new genus
}

\author{
Alan R. Lord, M. Cristina Cabral, and Dan L. Danielopol \\ Acta Palaeontologica Polonica 65 (2), 2020: 313-349 doi:https://doi.org/10.4202/app.00632.2019
}

Sieve-type normal pore canals (StPC) occur commonly in living and fossil cytheroid ostracods but their biological function(s) and evolutionary history are poorly known. The new genus Minyocythere and its four species: Minyocythere macroporosa sp. nov., M. angulata sp. nov., M. maculosa, and M. tuberculata from the Middle Jurassic have StPC prominently developed, display a range of normal pore canals, and provide a context for review of the geological record and palaeobiological potential of these structures, and their application as a taxonomic tool compared with classical approaches. The related Cretaceous genus Dolocythere is reviewed and Dolocythere amphistiela sp. nov. described. The significance of StPC for comparative morphology, systematics, palaeobiology and environmental interpretation are discussed. The range of normal pore canals observed, including StPC, is greater than previously described and several types can occur on one animal implying different life functions. The potential of normal pore canals especially StPC for systematic use is established although good preservation is essential. The functional significance of normal pore canals and their setae must be verified with living material before their evolutionary history can be deduced and their application to palaeoenvironmental interpretation and modern environmental monitoring enhanced.

Key words: Ostracoda, Cytheroidea, normal pore canals, systematics, Jurassic, Cretaceous, Europe.

Alan R. Lord [alan.lord@ senckenberg.de, OrcidID: ARL 0000-0002-0008-7746],

Senckenberg Forschungsinstitut Frankfurt, Senckenberganlage 25, D-60325

Frankfurt-am-Main, Germany. M. Cristina Cabral [mccabral@fc.ul.pt, OrcidID: 0000-0001-8717-4043], Universidade de Lisboa, Faculdade de Ciências, Departamento de Geologia e Instituto Dom Luiz (IDL), Campo Grande, C6, 4º 1749-016 Lisboa, Portugal. Dan Luca Danielopol [dan.danielopol@uni-graz.at, OrcidID: 0000-0003-3968-5564], Karl-Franzens University, Institute of Earth Sciences, Department of Geology and Palaeontology, Heinrichstrasse 26, A-8010 Graz, Austria. 
This is an open-access article distributed under the terms of the Creative Commons

Attribution License (for details please see creativecommons.org), which permits unrestricted use, distribution, and reproduction in any medium, provided the original author and source are credited.

For Full text $(2,769.8 \mathrm{kB})$ 